\title{
Glomerular hyperfiltration in Yemeni children with sickle cell disease
}

\author{
Abdul-Wahab M Al-Saqladi* and Fatima E Al-Musawa² \\ ${ }^{1}$ Pediatric Department, Faculty of Medicine and Health Sciences, University of Aden, Yemen \\ ${ }^{2}$ Pediatric Department, Al-Sadaqa General Teaching Hospital, Aden, Yemen
}

\section{Abstract}

Background: Glomerular hyperfiltration $(\mathrm{GH})$ is a common feature of sickle cell nephropathy (SCN) starting at infancy and represents an early marker of incipient glomerular injury and renal dysfunction.

Methods: This study aimed to determine the prevalence and correlates of $\mathrm{GH}$ among children ( $\leq 16$ years) with sickle cell disease (SCD) at their steady state, recruited over 6 months at the Pediatric Outpatient Clinic in Al-Sadaqa General Teaching Hospital, Aden, Yemen. Glomerular filtration rate (eGFR) was estimated using the Schwartz formula. Data on clinical history, anthropometry, blood pressure (BP) and laboratory investigations were collected.

Results: Of 101 children (mean age $7.2 \pm 3.9$ years), 65 (64.4\%) were males. The prevalence of $\mathrm{GH}$ was observed in 36 (35.6\%) children, who were significantly older (10.7 \pm 3.2 vs. $5.2 \pm 2.7$ years, $p<0.001)$ and had a lower fetal Hb level $(5 \pm 3.3$ vs. $9 \pm 7.1, p=0.02)$. All children were normotensive, but hyperfiltrating children showed significantly higher systolic $(97.2 \pm 7.3 \mathrm{vs}$. $89.7 \pm$ $5.2 \mathrm{mmHg}$ ) and diastolic pressure $(55.1 \pm 5.0 \mathrm{vs} .49 \pm 4.3 \mathrm{mmHg}$ ) (all $p<0.001)$. Among evaluated children, $25.7 \%$ had hyperfiltration alone, whereas $9.9 \%$ had an associated microalbuminuria (MA), and no significant difference in eGFR between those with and without MA (158.4 $\pm 33.7 \mathrm{vs}$. $160.7 \pm 29.8 \mathrm{ml} / \mathrm{min} / 173 \mathrm{~m}^{2}, p=0.84$ ).

Conclusion: This study demonstrated a relatively high prevalence of GH in Yemeni children with SCD that increased with age. Recognition of hyperfiltration and other early markers of nephropathy in this population could help to develop renal protective strategies to prevent progressive loss of kidney function.

\section{Introduction}

Sickle cell disease (SCD) is the most common hemoglobinopathies that affect more than 5 million individuals worldwide, with estimated annual birth over 300,000 children [1]. SCD is consider a multisystem disease adversely affects many body organs including the kidneys. Kidney involvement is collectively known as Sickle cell nephropathy (SCN), which is a serious complication associated significantly with increased risk for morbidity and mortality across all age groups [2,3]. SCN encompasses numerous structural and functional abnormalities with widely variable manifestations including hyposthenuria, glomerular hyperfiltration, hematuria, distal renal tubular acidosis, and subsequently albuminuria [4]. In SCD patients at a poorly oxygenated tissue, particularly renal medulla, hypoxia, hyperosmolarity and acidosis, promote repeated sickling of red cells with ischemic-reperfusion injury and

\section{More Information}

*Address for Correspondence:

Dr. Abdul-Wahab M Al-Saqladi, Department of Pediatrics, Faculty of Medicine and Health Sciences, University of Aden, Yemen, P.O. Box 6032 Khormaksar, Aden, Yemen,

Tel/Fax: +967(2)384260;

Email: asaqladi@yahoo.com

Submitted: November 23, 2020

Approved: January 10, 2021

Published: January 12, 2021

How to cite this article: Al-Saqladi AWM, Al-Musawa FE. Glomerular hyperfiltration in Yemeni children with sickle cell disease. J Clini Nephrol. 2021; 5: 001-007.

DOI: 10.29328/journal.jcn.1001065

Copyright: (๑ 2021 Al-Saqladi AWM, et al. This is an open access article distributed under the Creative Commons Attribution License, which permits unrestricted use, distribution, and reproduction in any medium, provided the original work is properly cited.

Keywords: Sickle cell disease; Sickle cell nephropathy; Glomerular hyperfiltration; Albuminuria; eGFR; Blood pressure

Abbreviations: ACS: Acute Chest Syndrome; BMI: Body Mass Index; BP: Blood Pressure; BUN: Blood Urea Nitrogen; eGFR: Estimated GFR; GFR: Glomerular Filtration Rate; GH; Glomerular Hyperfiltration; HU: Hydroxyurea; MA: Microalbuminuria; MAP: Mean Arterial Pressure; PP: Pulse Pressure; SCD: Sickle Cell Disease; SCN: Sickle Cell Nephropathy; SCr: Serum Creatinine; SNGFR: Single Nephron Glomerular Filtration Rate; VOC: VasoOcclusive Crisis

Check for updates

OPEN ACCESS micro-infarctions that consequently resulted in kidney damage [5].

Glomerular hyperfiltration (GH) is a common early finding in SCN, indicating glomerular injury starting as early as the first year of life, in otherwise asymptomatic patients $[5,6]$. Previous studies in SCD showed that eGFR increases during early childhood, plateaus during adolescents and then begins to decline with increasing age $[7,8]$. A varying prevalence of GH among children with SCD has been reported in a range 33\% to $76 \%$ [9-12]. Current evidence provided by a longitudinal cohort study of 91 children with SCD, showed glomerular hyperfiltration to precede the development of persistent albuminuria, and children with early hyperfiltration are predispose to develop early microalbuminuria [13]. Microalbuminuria is another initial 
marker of SCN tends to increase with age in parallel to decline of GFR [14], and it has been reported at a rate ranged between $11.3 \%-51.3 \%$ in children, and up to $68 \%$ in adults [15].

Although the etiology and pathogenesis of glomerular injury in SCD are not completely understood [3], hyperfiltration is assumed to occur at a single nephron level, therefore increase in single nephron glomerular filtration rate (SNGFR) is a key indicator of renal function that determined by glomerular plasma flow rate, the transcapillary hydraulic pressure gradient, the glomerular ultrafiltration coefficient (kf), and plasma oncotic pressure [6]. Hyperfiltration in SCD is principally driven by increased glomerular plasma flow rate and (kf), while elevation in transcapillary hydraulic pressure gradient values are marginal [16]. The increased in the glomerular plasma flow in SCD is accompanied by increased in both renal blood flow and GFR. Renal blood flow was found to be increased by as much as 50\% in SCD patients more than normal subjects [17]. Elevations in SNGFR first lead to intra-glomerular hypertension and pressurerelated injury [13]. Ongoing glomerular injury leads to the development of proteinuria as well as the progression to chronic kidney disease [8]. Recent evidence from multiple retrospective analyses of renal biopsies indicated by overt proteinuria and/or elevated serum creatinine in 36 SCD pediatric patients has revealed structural changes with abnormal findings in all biopsies, and the most common findings were mesangial proliferation with hemosiderin deposits (75\%), and glomerular hypertrophy (58\%), followed by focal segmental glomerulosclerosis (30\%) and membranoproliferative glomerulonephritis (16\%) [18].

Although, GH in SCD patients has been widely reported, there is paucity of information about hyperfiltration in children with SCD in the Arab region and none from Yemen. The primary aim of this study is to determine the prevalence of $\mathrm{GH}$ and to analyze its correlates in a group of Yemeni children with SCD in their steady state.

\section{Materials and methods}

The study protocol was reviewed and approved by the Institution Ethics Committee. Agreement for participation was obtained by asking a verbal consent from parents or close caregiver for all participant and children assents were also obtained, when appropriate. Anonymity and confidentiality of information were maintained.

\section{Study design and setting}

This is a cross-sectional, descriptive study conducted in Al-Sadaqa General Teaching Hospital, Pediatric Department during a time period of 6 months (September 2014 to February 2015). This hospital is the main pediatric hospital in Aden, South Yemen. It is a public health facility serving people from Aden and adjacent governorates, and provides medical care for the majority of pediatric patients with SCD in this locality. The study included consequently eligible SCD children with confirmed $\mathrm{Hb}$ SS by $\mathrm{Hb}$ electrophoresis, who were $\leq 16$ year of age, while in their steady state and attended for regular health maintenance visits.

\section{Data collection}

Data were collected using a pre-structured questionnaire, through direct interview with the closet caretaker of the child, the mother in most instances. A child was considered in steady state if symptom free without fever, acute illness or crisis and received no blood transfusion at least in the previous two weeks. Exclusion criteria include children who had been involved in competitive/exercise in the 12 hours preceding sample collection, those with fever at time of presentation or history of febrile illness, hospitalization, blood transfusion, and painful crises within the preceding 2 weeks. Adolescent with ongoing menses or vaginal or penile discharge, or findings suggestive urinary tract infection, history of pre-existing renal disease, diabetes mellitus, hypertension or history of drug intake like angiotensin converting enzyme inhibitor and angiotensin II receptor blockers were also excluded. All enrolled children were not on chronic transfusion program or hydroxyurea (HU) therapy.

Each child was evaluated thoroughly and data were obtained on demographic characteristics, drug therapy, disease complications and frequency of clinical events during the previous year, on particular, number of painful crisis, hospital admission, and blood transfusion. Data were cross checked with hospital records for those with previous hospital admission.

All children were subjected to full clinical examination. Systemic blood pressure (BP) was measured at the time of the interview by auscultatory method using mercury sphygmomanometer with appropriate cuff size covering two thirds of the right upper arm circumference while the arm was resting at the same level as the heart. Two measures were taken on arrival and before departure, and after at least 5 minutes of quite rest. The mean of the two readings was considered the participant BP. The results were interpreted based on the currently published SCD-specific BP tables [19]. Pulse pressure (PP) was calculated as the difference between systolic and diastolic BP. Mean arterial pressure (MAP) was determined as [(2*DBP+SBP $) / 3]$. Body weight and length/ height were taken for every participant while in light clothing, without footwear and in correct position during anthropometric measurements. Body mass index (BMI) was calculated by dividing body weight in kg over length/height in $\mathrm{m}^{2}$.

Venous blood sample was collected from each patient by aseptic venipuncture on the same clinic visit, after interview completed. This blood sample was used for determination 
of hemoglobin level; leucocytes count (WBC), platelets, hematocrit and blood urea nitrogen (BUN) using standard methods. For serum creatinine (SCr) evaluation, the Colorimetric Jaffe`s method was used. Microalbuminuria was tested on a random midstream clean catch urine sample using the Micral-Test urine dipsticks, as recommended by the manufacturers (Roche Diagnostic GmbH, Mannheim, Germany).

Glomerular filtration rate (GFR) was estimated for each patient using the Schwartz serum creatinine based formula: eGFR $=\mathrm{K} \times \mathrm{L} / \mathrm{SCr}$. eGFR is an estimated GFR in milliliters per minute per $1.73 \mathrm{~m}^{2}$, L is height in centimeters, $\mathrm{SCr}$ is serum creatinine in milligrams per deciliter, and $\mathrm{K}$ is an empirical constant determined by comparing the $\mathrm{L} / \mathrm{SCr}$ ratio against measured GFR. The value of $\mathrm{K}$ is 0.55 for children and adolescent girls, and 0.7 for adolescent boys [20]. Glomerular hyperfiltration was defined as an eGFR $>1 \mathrm{SD}$ above the normal mean for age, $\left(104 \pm 20 \mathrm{ml} / \mathrm{min} / 1.73 \mathrm{~m}^{2}\right)$, as previously used in different clinical conditions [21], including pediatric SCD [7, 22].

\section{Statistical analysis}

Data analysis was performed using SPSS Statistics for Windows, version 25 (IBM Corp., Armonk, NY, USA). Categorical variables were expressed as absolute frequencies and percentages. Continuous variables were tested for normalcy by the Shapiro-Wilk test and presented as mean \pm standard deviation for normally distributed data. Differences between groups were assessed accordingly using Chi-square test, Fisher's exact test, Student $t$ test as appropriate. eGFR was evaluated as continuous variable and $\mathrm{GH}$ as dichotomous (present and absent). A multivariate logistic regression was employed to identify the independent variables associated with GH. A significant level was set as $p<0.05$ for all analysis.

\section{Results}

\section{Clinical and biological parameters}

A total of 101 children with SCD were recruited in this study, $65(64.4 \%)$ male and $36(34.6 \%)$ female, giving an $\mathrm{M}: \mathrm{F}$ ratio of 1.8:1. The overall mean age was $7.2 \pm 3.9$ years, (range 6 months-16 years). Majority 72 (71.3\%) were children 10 years and below. All children were normotensive for both systolic and diastolic BP $\left(<90^{\text {th }}\right.$ percentile for age and gender) based on SCD-specific BP tables, with mean systolic and diastolic BP measurements of $92.6 \pm 6.7$ and $51.5 \pm 5.2 \mathrm{~mm} \mathrm{Hg}$, respectively. Mean values of BUN and serum creatinine were $0.5 \pm 0.1$ and $25 \pm 7.4$, respectively, and all children had their test values that were within the normal reference range. Other clinical and laboratory characteristics of enrolled children are shown in table 1.

\section{Glomerular filtration estimates}

The mean eGFR was $122.8 \pm 34.6 \mathrm{ml} / \mathrm{min} / 1.73 \mathrm{~m}^{2}$ (range: 85.8 - $239.8 \mathrm{ml} / \mathrm{min} / 1.73 \mathrm{~m}^{2}$ ) and was normally distributed

\begin{tabular}{|c|c|c|c|c|}
\hline Variable & $\begin{array}{c}\text { All } \\
(n=101)\end{array}$ & $\begin{array}{c}\text { Male } \\
(n=65)\end{array}$ & $\begin{array}{l}\text { Female } \\
(n=36)\end{array}$ & $p$ value \\
\hline Age, years & $7.2 \pm 3.9$ & $7.6 \pm 4.0$ & $6.5 \pm 3.7$ & 0.18 \\
\hline Weight, kg & $18.5 \pm 8.0$ & $19.1 \pm 8.4$ & $17.4 \pm 7.3$ & 0.56 \\
\hline Height, $\mathrm{cm}$ & $110.8 \pm 20.2$ & $112.2 \pm 20.7$ & $108.1 \pm 19.1$ & 0.54 \\
\hline $\mathrm{BMI}, \mathrm{kg} / \mathrm{m}^{2}$ & $14.5 \pm 2.6$ & $14.6 \pm 2.7$ & $14.3 \pm 2.4$ & 0.07 \\
\hline $\mathrm{SBP}, \mathrm{mmHg}$ & $92.6 \pm 6.7$ & $93 \pm 7$ & $92 \pm 7$ & 0.41 \\
\hline $\mathrm{DBP}, \mathrm{mmHg}$ & $51.5 \pm 5.2$ & $52 \pm 6$ & $51 \pm 4$ & 0.37 \\
\hline $\mathrm{PP}, \mathrm{mmHg}$ & $41 \pm 6.3$ & $41 \pm 6$ & $41.2 \pm 7$ & 0.83 \\
\hline MAP, $\mathrm{mmHg}$ & $65.1 \pm 5$ & $65.5 \pm 5.4$ & $64.4 \pm 4.3$ & 0.04 \\
\hline VOC, n/year & $3.4 \pm 2$ & $3.3 \pm 2$ & $3.5 \pm 2$ & 0.71 \\
\hline Blood transfusion, $n /$ year & $2.5 \pm 1.7$ & $2.6 \pm 1.9$ & $2.2 \pm 1.3$ & 0.26 \\
\hline Hospitalization, $n /$ year & $2.5 \pm 2$ & $2.8 \pm 2.3$ & $1.8 \pm 1.5$ & 0.85 \\
\hline Anemic crises, $n /$ year & $2.2 \pm 1.6$ & $2.5 \pm 1.8$ & $1.7 \pm 1.2$ & 0.11 \\
\hline ACS, $n(\%)$ & $27(26.7)$ & $20(19.8)$ & $7(6.9)$ & 0.21 \\
\hline Stroke, $n(\%)$ & $9(8.9)$ & $6(5.9)$ & $3(3)$ & 0.87 \\
\hline Enuresis $>5$ yrs, $n(\%)$ & $27(42.2)$ & $18(28.1)$ & $9(14.1)$ & 0.73 \\
\hline $\mathrm{Hb}, \mathrm{g} / \mathrm{dl}$ & $7.2 \pm 1.0$ & $7.2 \pm 0.98$ & $7.1 \pm 1.10$ & 0.65 \\
\hline Hct, \% & $22.2 \pm 3$ & $22.4 \pm 2.9$ & $21.8 \pm 3.1$ & 0.41 \\
\hline WBC, $\times 10^{9} / \mathrm{L}$ & $11.5 \pm 4$ & $11.5 \pm 3.9$ & $11.7 \pm 4.2$ & 0.67 \\
\hline Platelets $\times 10^{9} / \mathrm{L}$ & $338.3 \pm 140.5$ & $337.3 \pm 150.4$ & $340 \pm 122.7$ & 0.92 \\
\hline $\mathrm{HbF}, \%$ & $8.1 \pm 5.8$ & $7.4 \pm 5.8$ & $9.4 \pm 5.7$ & 0.93 \\
\hline BUN, mg/dl & $25.0 \pm 7.4$ & $24.4 \pm 7.7$ & $26.4 \pm 6.6$ & 0.19 \\
\hline S. creatinine, mg/dl & $0.5 \pm 0.10$ & $0.6 \pm 0.10$ & $0.5 \pm 0.10$ & 0.06 \\
\hline eGFR, $\mathrm{ml} / \mathrm{min} / 1.73 \mathrm{~m}^{2}$ & $122.8 \pm 34.6$ & $125.4 \pm 37$ & $118.1 \pm 29.5$ & 0.31 \\
\hline
\end{tabular}

over this range. According to the definition used in this study, GH occurred in 36 children (35.6\%), while 65 children $(64.4 \%)$ had non elevated eGFR. Among children with hyperfiltration, there were $24(66.7 \%)$ males compared to $12(33.3 \%)$ females, without significant difference between gender $(p=0.71)$.

\section{Factors associated with hyperfiltration}

To identify the factors potentially associated with $\mathrm{GH}$ we compared patients with and without hyperfiltration as shown in table 2 . The hyperfiltrating children were older, with mean age $(10.7 \pm 3.2$ vs. $5.2 \pm 2.7$ years, $p<0.001)$ and there was significant evidence of a relationship between eGFR and age $(r=0.713, p<0.001)$ (Figure 1). Moreover, hyperfiltrating children had significantly higher systolic $(97.2 \pm 7.3$ vs. $89.7 \pm 5.2)$ and diastolic pressure $(55.1 \pm 5.0$ vs. $49 \pm 4.3$ ) (all $p<0.001)$. There were no significant differences in relation to frequency of clinical events (painful crises, blood transfusions and hospitalizations) between patients with and without hyperfiltration.

Among patients with GH, 10 (9.9\%) patients had MA compared to $26(25.7 \%)$ with no MA, the mean age of these two groups was not statistically different. However, MA was highly prevalent in patients without hyperfiltration $(72.2 \%$ vs. 27.8\%, $p=0.004$ ) (Figure 2). There were no significant differences in the mean age of patients with hyperfiltration and positive MA compared to those with hyperfiltration and negative MA $(10.4 \pm 3.0$ vs. $10.8 \pm 3.4$ years respectively, $p=0.76$ ). 
Univariate analysis showed that SBP, DBP and PP were of significant predictors of $\mathrm{GH}$, and patients with higher SBP, DBP and PP were more likely to have GH at odds ratio of $0.79,0.77$ and 0.69 , respectively. In contrast, patients with higher $\mathrm{HbF}$ were 1.01 times less likely to have GH. There was no association between GH with frequency of blood transfusions, painful crises, hospitalizations, or MA. Among all factors associated with $\mathrm{GH}$ at univariate analysis, only height and BMI maintained an independent association by multiple regression analysis (Table 3).

Table 2: Clinical and laboratory findings in children with and without hyperfiltration.

\begin{tabular}{|c|c|c|c|}
\hline Variable & $\begin{array}{l}\text { Hyperfiltration } \\
\qquad(n=36)\end{array}$ & $\begin{array}{l}\text { No Hyperfiltration } \\
\qquad(n=65)\end{array}$ & $p$ value \\
\hline Age, years & $10.7 \pm 3.2$ & $5.2 \pm 2.7$ & $<0.001$ \\
\hline BMI, $\mathrm{kg} / \mathrm{m}^{2}$ & $15.1 \pm 3.2$ & $14.1 \pm 2.2$ & 0.06 \\
\hline $\mathrm{SBP}, \mathrm{mmHg}$ & $97.2 \pm 7.3$ & $89.7 \pm 5.2$ & $<0.001$ \\
\hline $\mathrm{DBP}, \mathrm{mmHg}$ & $55.1 \pm 5$ & $49.3 \pm 4.3$ & $<0.001$ \\
\hline $\mathrm{PP}, \mathrm{mmHg}$ & $43.3 \pm 7.2$ & $39.6 \pm 5.2$ & 0.01 \\
\hline MAP, $\mathrm{mmHg}$ & $69.3 \pm 4.5$ & $62.7 \pm 3.7$ & 0.02 \\
\hline VOC, n/year & $3.6 \pm 1.6$ & $3.3 \pm 2.2$ & 0.51 \\
\hline Blood transfusion, $n /$ year & $2.4 \pm 1.2$ & $2.5 \pm 1.3$ & 0.45 \\
\hline Hospitalization, $n /$ year & $2.3 \pm 1.8$ & $2.6 \pm 1.5$ & 0.24 \\
\hline Anemic crises, $n$ /year & $2.5 \pm 1.7$ & $2.4 \pm 1.2$ & 0.51 \\
\hline ACS, $n(\%)$ & $20(19.8)$ & $7(6.9)$ & 0.21 \\
\hline Stroke, $n(\%)$ & $4(3.9)$ & $5(4.9)$ & 0.77 \\
\hline Enuresis $>5 \mathrm{yrs}, n(\%)$ & $13(20.3)$ & $14(21.9)$ & 0.79 \\
\hline $\mathrm{Hb}, \mathrm{g} / \mathrm{dl}$ & $7.4 \pm 1$ & $7.2 \pm 1.0$ & 0.31 \\
\hline Hct, \% & $22.6 \pm 2.7$ & $22.0 \pm 1.0$ & 0.39 \\
\hline WBC, $\times 10^{9} / L$ & $10.8 \pm 2.7$ & $12 \pm 4.6$ & 0.10 \\
\hline Platelets, $\times 10^{9} / \mathrm{L}$ & $394 \pm 122.8$ & $335 \pm 150.3$ & 0.77 \\
\hline $\mathrm{HbF}, \%$ & $5 \pm 3.3$ & $9 \pm 7.10$ & 0.02 \\
\hline BUN, mg/dl & $22.8 \pm 7.9$ & $26.4 \pm 6.9$ & 0.01 \\
\hline S. creatinine, $\mathrm{mg} / \mathrm{dl}$ & $0.5 \pm 0.1$ & $0.6 \pm 0.10$ & 0.01 \\
\hline GFR, $\mathrm{ml} / \mathrm{min} / 1.73 \mathrm{~m}^{2}$ & $160 \pm 30.4$ & $102.2 \pm 12.4$ & $<0.001$ \\
\hline \multicolumn{4}{|c|}{$\begin{array}{l}\text { SBP: Systolic BP; DBP: Diastolic BP; PP: Pulse Pressure; MAP: Mean Arteria } \\
\text { Pressure; VOC: Vaso-Occlusive Crisis; ACS: Acute Chest Syndrome }\end{array}$} \\
\hline
\end{tabular}

Table 3: Univariate and multivariable logistic regression of factors associated with $\mathrm{GH}$.

\begin{tabular}{|c|c|c|c|c|}
\hline \multirow{2}{*}{ Variable } & \multirow{2}{*}{ Odds ratio } & \multirow{2}{*}{$p$} & \multicolumn{2}{|c|}{$95 \%$ confidence interval } \\
\hline & & & Lower bound & Upper bound \\
\hline \multicolumn{5}{|l|}{ Univariate model } \\
\hline Age, years & 0.55 & $<0.001$ & 0.435 & 0.692 \\
\hline Male gender & 0.85 & 0.71 & 0.363 & 2.012 \\
\hline VOC & 0.91 & 0.37 & 0.730 & 1.125 \\
\hline Blood transfusion & 1.23 & 0.15 & 0.925 & 1.644 \\
\hline Hospitalization & 1.19 & 0.11 & 0.958 & 1.498 \\
\hline Anemic crises & 1.22 & 0.15 & 0.928 & 1.618 \\
\hline Weight, kg & 0.73 & $<0.001$ & 0.657 & 0.832 \\
\hline Height, $\mathrm{cm}$ & 0.88 & $<0.001$ & 0.836 & 0.927 \\
\hline $\mathrm{BMI}, \mathrm{kg} / \mathrm{m}^{2}$ & 0.86 & 0.06 & 0.734 & 1.012 \\
\hline $\mathrm{SBP}, \mathrm{mmHg}$ & 0.79 & $<0.001$ & 0.723 & 0.882 \\
\hline DBP, $\mathrm{mmHg}$ & 0.77 & $<0.001$ & 0.693 & 0.861 \\
\hline $\mathrm{PP}, \mathrm{mmHg}$ & 0.69 & $<0.001$ & 0.604 & 0.800 \\
\hline MAP, $\mathrm{mmHg}$ & 0.95 & 0.14 & 0.891 & 1.017 \\
\hline $\mathrm{Hb}, \mathrm{g} / \mathrm{dl}$ & 0.81 & 0.30 & 0.532 & 1.217 \\
\hline BUN, mg/dl & 1.07 & 0.02 & 1.011 & 1.139 \\
\hline S. creatinine. $\mathrm{mg} / \mathrm{dl}$ & 0.52 & 0.02 & 0.475 & 1.860 \\
\hline $\mathrm{HbF}, \%$ & 1.01 & 0.03 & 1.007 & 1.153 \\
\hline Microalbuminuria, mg/L & 1.33 & 0.53 & 0.455 & 3.246 \\
\hline \multicolumn{5}{|l|}{ Multivariate model } \\
\hline Height, $\mathrm{cm}$ & 0.53 & 0.02 & 0.307 & 0.919 \\
\hline $\mathrm{BMI}, \mathrm{kg} / \mathrm{m}^{2}$ & 0.13 & 0.04 & 0.021 & 0.911 \\
\hline
\end{tabular}

VOC: Vaso-Occlusive Crisis; SBP: Systolic BP; DBP: Diastolic BP; PP: Pulse Pressure; MAP: Mean Arterial Pressure

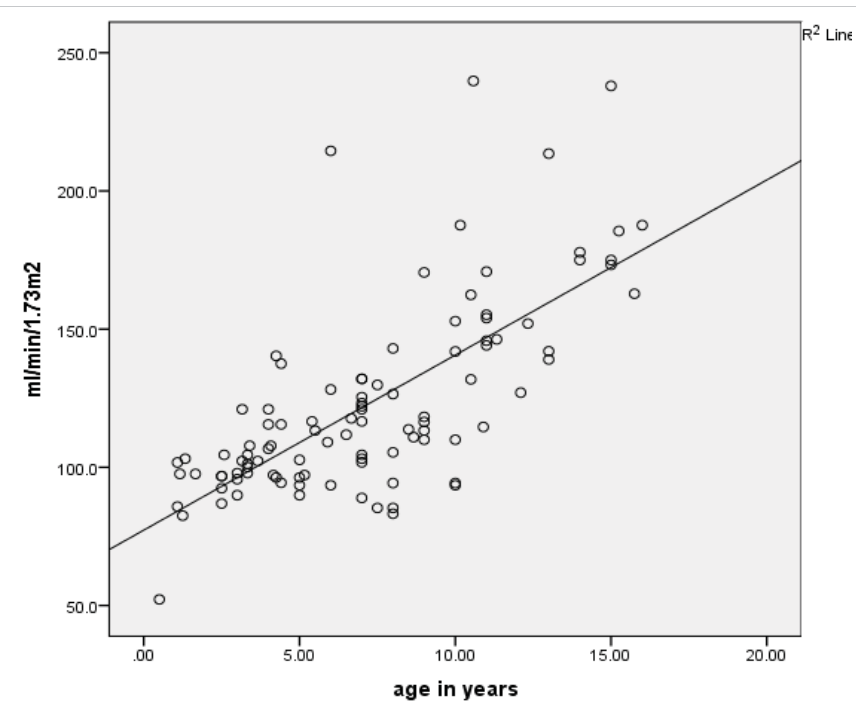

Figure 1: Correlation between eGFR and age of children with sickle cell disease.

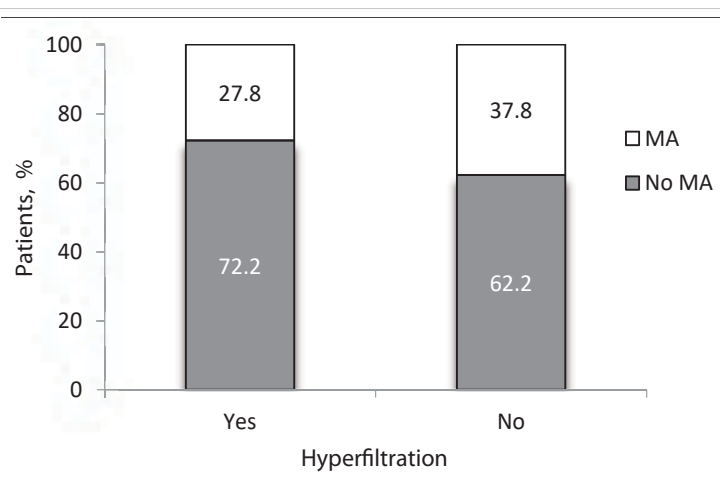

Figure 2: Distribution of children with and without hyperfiltration according to MA.

\section{Discussion}

Glomerular filtration rate is a reliable indicator of renal function in children and adolescent and is a critical measure for the diagnosis of acute and chronic kidney impairment [20]. Although measured GFR is more ideal and gives better result, it is recognized that it can be difficult to measure directly, and in young children, using eGFR such as Schwartz formula is suggested to be noninvasive and practical method with acceptable and comparable results [23]. To our knowledge, this is the first attempt to describe the prevalence of glomerular hyperfiltration and associated factors in children with SCD from Yemen. In the current study the mean eGFR was $122 \pm 34.6 \mathrm{ml} / \mathrm{min} / 1.73 \mathrm{~m}^{2}$, and there was no significant sex differences, which was comparable with data from Nigeria, where the mean eGFR of SCD children was $118 \pm$ $27.51 \mathrm{ml} / \mathrm{min} / 1.73 \mathrm{~m}^{2}$ [24], and no significant sex variation reported by one American study [10].

Thirty six children (35.6\%) in the present study had GH, this prevalence was consistent with 33.1\% [9] and 40\% [14] in Congolese children, where eGFR was estimated using the same method, but lower than $76 \%$ and $72.9 \%$ reported by two different American studies [7,10]. Variation in the prevalence rate of glomerular hyperfiltration between 
studies is not clearly understood, but it could be influenced by inconsistency in population characteristics, the methods used to estimate or measure GFR, and the cut-offs used to define hyperfiltration. In the American study [10] where hyperfiltration was reported in $73 \%$ of patients, the cut-off used $\left(120 \mathrm{ml} / \mathrm{min} / 1.73 \mathrm{~m}^{2}\right)$ was lower than our reference rate $(>1 \mathrm{SD}$ above the normal mean for age $104 \pm 20 \mathrm{ml} /$ $\mathrm{min} / 1.73 \mathrm{~m}^{2}$ ) and much lower than $140 \mathrm{ml} / \mathrm{min} / 1.73 \mathrm{~m}^{2}$ used in Congolese studies [9,14].

Our data demonstrated that a large proportion of children with SCD had GH even in early ages of life, and eGFR was strongly correlated with increase of age. Hyperfiltration in SCD was noted to start during infancy, as early as 9-19 months of age as described in the Pediatric Hydroxyurea Phase III Clinical Trail (Baby HUG) study, which confirmed that renal dysfunction in SCD measured by GFR elevation occurred from infancy [25]. Previous literatures reported that GFR tends to increase as the child gets older and may eventually decrease in young adult onwards $[7,26]$. In the current study the mean age of patients with hyperfiltration was significantly higher than those with no hyperfiltration, but there was no significant sex difference between the two groups. There are limited studies of glomerularhyperfiltration and its correlates in children with SCD, and among these studies, similar results were reported in Congolese SCD children, in which there was significant difference in the mean age between patients with and without hyperfiltration (10.2 \pm 4.1 vs. $7.9 \pm 4.3$ years respectively, $p<0.001)$ but without significant sex differences [14].

Patients with SCD have lower systemic blood pressure (BP) than normal population. Although the exact cause is still unknown, factors attributed include hyposthenuria and polyuria with excess loss of sodium and water, anemia with systemic vasodilation and decrease peripheral resistance, altered production of prostaglandins and nitric oxide (NO), and reduced vascular reactivity $[27,28]$. A mild elevation in $\mathrm{BP}$ even in a range that would considered normal for general population is known as relative hypertension, and has been linked to renal dysfunction and other SCD adverse effects $[19,27]$. Although all children were normotensive, both systolic and diastolic BP were correlated positively with eGFR in the present study and elsewhere [7], while another study found no such association [10]. The pulse pressure was also found to be significantly elevated in hyperfiltrating children in the present study, which is concur with results related pulse pressure to SCN and other cardiovascular complications, obtained from a large multisite study from the United States and the United Kingdom [29]. However, the significance of this finding in normotensive SCD patients needs to be confirmed and elaborated in further studies.

It is worth mentioning that $\mathrm{SCD}$ related clinical events did not differ significantly between patients with and without hyperfiltration. Other few previous studies reported on the relationship between some SCD related complications and GFR, and found GFR did not relate with ACS and stroke [10]. One study reported a positive correlation between eGFR and frequency of blood transfusions [30], but other researchers found no difference between patients with and without hyperfiltration [14]. Absence of such correlation was assumed to be resulted from the relatively small sample size or the factors contributing to the development of these complications may be different than those related to renal damage [10]. Interesting finding, is that $\mathrm{HbF}$ level was significantly lower in patients with hyperfiltration in the present study. $\mathrm{HbF}$ is a known important determinant of SCD severity, unfortunately we couldn't find comparative result, especially in children not on hydroxyurea therapy. Notably, in a follow up study (HUSTLE), 23 children with SCD were followed for three years and received HU treatment, in an approach suggested to diminish renal involvement in SCD patients. In 18/23 of these children significant reduction in their GFR $\left(167 \pm 46\right.$ to $\left.145 \pm 27 \mathrm{~mL} / \mathrm{min} / 1.73 \mathrm{~m}^{2}\right)$ was recorded [31]. This finding proposed that HU could ameliorate renal damage in SCD through the protective role of $\mathrm{HbF}$.

In this study both SCr and BUN levels were within normal reference range, but tend to be lower in those with GH, which is consistent with other report [14]. SCr is increases slowly and late relative to the amount of lost filtration function, beside the influence of other factors such as tubular secretion, age, gender, muscle mass and diet [32] .

The relationship between hyperfiltration and MA was not confirmed in this study which was consistent with other reports $[14,31,33]$. Contrasted to findings from a Nigerian study [24], where majority of children with MA had elevated eGFR 62/84 (73.8\%), and the risk of MA was one and half times more in children with hyperfiltration compared to those without. Interestingly, a novel longitudinal pediatric SCD cohort for 91 children with SCD reported that $23 \%$ of patients with hyperfiltration was progressed to persistent albuminuria, compared to $3 \%$ with no hyperfiltration [13]. Consequently, researchers concluded that hyperfiltration precedes the development of persistent proteinuria in pediatric SCD patients and early intervention strategies should be adopted.

The present study has some limitations. The crosssectional design with its inherent drawbacks, physical and laboratory measurements were only performed once, although follow up study and repeated measurements are better. We estimated GFR using creatinine based Schwartz formula, despite of its shortcoming and measured GFR would be better but not available in our locality at present, and eGFR is still widely utilized in medical literature as acceptable practical method. Markers of hemolysis assumed to be associated with GH had not been evaluated in this study. 


\section{Conclusion}

The present study demonstrated a relatively high prevalence of glomerular hyperfiltration in children with SCD living in Yemen, starting at early age. This could predispose them to potential risk of progressive glomerulopathy and renal insufficiency later in adult life. GH was found to be strongly correlated with increase age, and inversely related to $\mathrm{HbF}$ levels. Further longitudinal studies are needed to establish the best screening methods for early detection of kidney dysfunction and to address appropriate effective interventions aiming to preserve renal function in this vulnerable population.

\section{References}

1. Piel FB, Patil AP, Howes RE, Nyangiri OA, Gething PW, et al. Global epidemiology of sickle haemoglobin in neonates: a contemporary geostatistical model-based map and population estimates. Lancet. 2013; 381: 142-151.

PubMed: https://pubmed.ncbi.nlm.nih.gov/23103089/

2. Olaniran KO, Eneanya ND, Nigwekar SU, Vela-Parada XF, Achebe $\mathrm{MM}$, et al. Sickle cell nephropathy in the pediatric population. Blood Purification. 2019; 47: 205-213.

PubMed: https://pubmed.ncbi.nlm.nih.gov/30517931/

3. Belisario AR, da Silva AA, Silva CV, de Souza LM, Wakabayashi EA, et al. Sickle cell disease nephropathy: an update on risk factors and potential biomarkers in pediatric patients. Biomark Med. 2019; 13: 967-987.

PubMed: https://pubmed.ncbi.nlm.nih.gov/31390894/

4. Hariri E, Mansour A, El Alam A, Daaboul Y, Korjian S, et al. Sickle cell nephropathy: an update on pathophysiology, diagnosis, and treatment. Int Urol Nephrol. 2018; 50: 1075-1083.

PubMed: https://pubmed.ncbi.nlm.nih.gov/29383580/

5. Naik RP, Derebail VK. The spectrum of sickle hemoglobin-related nephropathy: from sickle cell disease to sickle trait. Expert Rev Hematol. 2017; 10: 1087-1094.

PubMed: https://pubmed.ncbi.nlm.nih.gov/29048948/

6. Nath KA, Hebbel RP. Sickle cell disease: renal manifestations and mechanisms. Nat Rev Nephrol. 2015; 11: 161-171.

PubMed: https://pubmed.ncbi.nlm.nih.gov/25668001/

7. Aygun B, Mortier NA, Smeltzer MP, Hankins JS, Ware RE. Glomerular hyperfiltration and albuminuria in children with sickle cell anemia. Pediatr Nephrol. 2011; 26: 1285-1290.

PubMed: https://pubmed.ncbi.nlm.nih.gov/21559933/

8. Hirschberg R. Glomerular hyperfiltration in sickle cell disease. Clin J Am Soc Nephrol. 2010; 5: 748-745.

PubMed: https://pubmed.ncbi.nlm.nih.gov/20299367/

9. Aloni MN, Ngiyulu RM, Gini-Ehungu JL, Nsibu CN, et al. Renal function in children suffering from sickle cell disease: challenge of early detection in highly resource-scarce settings. PLoS One. 2014; 9: e96561.

PubMed: https://pubmed.ncbi.nlm.nih.gov/24810610/

10. Bodas P, Huang A, O'Riordan MA, Sedor JR, Dell KM. The prevalence of hypertension and abnormal kidney function in children with sickle cell disease-a cross sectional review. BMC nephrology. 2013; 14 : 237-243.

PubMed: https://pubmed.ncbi.nlm.nih.gov/24168027/

11. Marouf $\mathrm{R}$, Mojiminiyi $\mathrm{O}$, Abdella $\mathrm{N}$, Kortom M, Al Wazzan $\mathrm{H}$. Comparison of renal function markers in Kuwaiti patients with sickle cell disease. J Clin Pathol. 2006; 59: 345-351.

PubMed: https://pubmed.ncbi.nlm.nih.gov/16567469/
12. Haymann J-P, Stankovic K, Levy P, Avellino V, Tharaux P-L, et al. Glomerular hyperfiltration in adult sickle cell anemia: a frequent hemolysis associated feature. Clin J Am Soc Nephrol. 2010; 5: 756-761. PubMed: https://pubmed.ncbi.nlm.nih.gov/20185605/

13. Lebensburger JD, Aban I, Pernell B, Kasztan M, Feig DI, et al. Hyperfiltration during early childhood precedes albuminuria in pediatric sickle cell nephropathy. Am J Hematol. 2019; 94: 417-423. PubMed: https://pubmed.ncbi.nlm.nih.gov/30592084/

14. Aloni MN, Ngiyulu RM, Ekulu PM, Mbutiwi FI, Makulo JR, et al. Glomerular hyperfiltration is strongly correlated with age in Congolese children with sickle cell anaemia. Acta Paediatr. 2017; 106: 819-824. PubMed: https://pubmed.ncbi.nlm.nih.gov/28218952/

15. Al-Musawa FE, Al-Saqladi AM. Prevalence and correlates of microalbuminuria in Yemeni children with sickle cell disease. Saudi J Kidney Dis Transpl. 2019; 30: 832-842.

PubMed: https://pubmed.ncbi.nlm.nih.gov/31464240/

16. Schmitt F, Martinez F, Brillet G, Giatras I, Choukroun G, et al. Early glomerular dysfunction in patients with sickle cell anemia. Am J Kidney Dis. 1998; 32: 208-214.

PubMed: https://pubmed.ncbi.nlm.nih.gov/9708603/

17. Alhwiesh A. An update on sickle cell nephropathy. Saudi J Kidney Dis Transp. 2014; 25: 249-265.

PubMed: https://pubmed.ncbi.nlm.nih.gov/24625990/

18. Zahr RS, Yee ME, Weaver J, Twombley K, Matar RB, et al. Kidney biopsy findings in children with sickle cell disease: a Midwest Pediatric Nephrology Consortium study. Pediatr Nephrol. 2019; 34: 1435-1445. PubMed: https://pubmed.ncbi.nlm.nih.gov/30945006/

19. Pegelow $\mathrm{CH}$, Colangelo L, Steinberg M, Wright EC, Smith J, et al. Natural history of blood pressure in sickle cell disease: risks for stroke and death associated with relative hypertension in sickle cell anemia. Am J Med. 1997; 102: 171-177.

PubMed: https://pubmed.ncbi.nlm.nih.gov/9217567/

20. Schwartz GJ, Work DF. Measurement and estimation of GFR in children and adolescents. Clin J Am Soc Nephrol. 2009; 4: 1832-1843. PubMed: https://pubmed.ncbi.nlm.nih.gov/19820136/

21. Piepsz A, Tondeur M, Ham H. Revisiting normal 51 Crethylenediaminetetraacetic acid clearance values in children. Eur J Nucl Med Mol Imaging. 2006; 33: 1477-1482.

22. Paula RPd, Nascimento AF, Sousa SMB, Bastos PRV, Barbosa AAL. Glomerular filtration rate is altered in children with sickle cell disease: a comparison between $\mathrm{Hb}$ SS and $\mathrm{Hb}$ SC. Rev Bras Hematol Hemoter. 2013; 35: 349-351.

PubMed: https://www.ncbi.nlm.nih.gov/pmc/articles/PMC3832316/

23. Alvarez O, Miller ST, Wang WC, Luo Z, McCarville MB, et al. Effect of hydroxyurea treatment on renal function parameters: results from the multicenter placebo controlled BABY HUG clinical trial for infants with sickle cell anemia. Pediatr Blood Cancer. 2012; 59: 668-674. PubMed: https://pubmed.ncbi.nlm.nih.gov/22294512/

24. Ocheke I, Mohamed S, Okpe E, Bode-Thomas F, McCullouch M. Microalbuminuria risks and glomerular filtration in children with sickle cell anaemia in Nigeria. Ital J Pediatr. 2019; 45: 143-148.

PubMed: https://pubmed.ncbi.nlm.nih.gov/31718702/

25. Ware RE, Rees RC, Sarnaik SA, lyer RV, Alvarez OA, et al. Renal function in infants with sickle cell anemia: baseline data from the BABY HUG trial. J Pediatr. 2010; 156: 66-70. e61. PubMed: https://pubmed.ncbi.nlm.nih.gov/19880138/

26. Wigfall DR, Ware RE, Burchinal MR, Kinney TR, Foreman JW. Prevelance and clinical correlates of glomerulopathy in children with sickle cell disease. J Pediatr. 2000; 136: 749-753.

PubMed: https://pubmed.ncbi.nlm.nih.gov/10839871/

27. Gordeuk VR, Sachdev V, Taylor JG, Gladwin MT, Kato G, et al. Relative systemic hypertension in patients with sickle cell disease is associated with risk of pulmonary hypertension and renal insufficiency. 
Am J Hematol. 2008; 83: 15-18.

PubMed: https://pubmed.ncbi.nlm.nih.gov/17696198/

28. Pikilidou M, Yavropoulou M, Antoniou M, Papakonstantinou E, Pantelidou D, et al. Arterial Stiffness and Peripheral and Central Blood Pressure in Patients With Sickle Cell Disease. J Clin Hypertens (Greenwich). 2015; 17: 726-731.

PubMed: https://pubmed.ncbi.nlm.nih.gov/25991400/

29. Novelli EM, Hildesheim M, Rosano C, Vanderpool R, Simon M, et al. Elevated pulse pressure is associated with hemolysis, proteinuria and chronickidneydiseaseinsicklecelldisease.PLoSOne.2014;9:e114309. PubMed: https://pubmed.ncbi.nlm.nih.gov/25478953/

30. Nnaji UM, Ogoke CC, Okafor HU, Achigbu KI. Sickle Cell Nephropathy and Associated Factors among Asymptomatic Children with Sickle
Cell Anaemia. Int J Pediatr. 2020; 2020: 1286432.

PubMed: https://pubmed.ncbi.nlm.nih.gov/32908550/

31. Aygun B, Mortier NA, Smeltzer MP, Shulkin BL, Hankins JS, et al. Hydroxyurea treatment decreases glomerular hyperfiltration in children with sickle cell anemia. Am J Hematol. 2013; 88: 116-119. PubMed: https://pubmed.ncbi.nlm.nih.gov/23255310/

32. Al-Saqladi AM. Acute Kidney Injury: New Definitions and Beyond. J Nephrol Therapeut. 2016; 06: 1-4.

33. King L, MooSang M, Miller M, Reid M. Prevalence and predictors of microalbuminuria in Jamaican children with sickle cell disease. Arch Dis Child. 2011; 96: 1135-1139.

PubMed: https://pubmed.ncbi.nlm.nih.gov/21965808/ 